\title{
Uma dinastia governante em Gezer? Leitura a partir das Cartas de Amarna*
}

\section{A ruling dynasty in Gezer? A reading based on Amarna Tablets}

\section{Una dinastía gobernante en Gezer? Lectura a partir de las Cartas de Amarna}

\author{
Carlos Mario Vásquez
}

\begin{abstract}
RESUMO
Neste artigo abordaremos as cartas de Amarna 267-272, 293, 298-300, 369 e 378, que tratam das correspondências dos governantes da Cidade-Estado de Gezer para o rei do Egito. Elas se referem ao período inicial do século 14 a.C., quando as relações entre os governantes das cidades-estados, no território de Canaã, eram marcadas por intensos conflitos e hostilidades. As cartas mencionam três governantes de Gezer: Milkilu, Ba'lu-dānu e Yapahu, caso único na correspondência de Amarna. Além de evidenciar os conflitos crescentes na região, as cartas também testemunham abundante atividade comercial entre Gezer e Egito e um rápido enfraquecimento do domínio egípcio na região de Canaã.

Palavras-chave: Cartas de Amarna, Egito, Gezer, Comércio, 'apîru
\end{abstract}

\begin{abstract}
This article addresses the Amarna Letters 267-272, 293, 298-300, 369, and 378, which were the correspondence exchanged between the rulers of City-State of Gezer and the king of Egypt. The letters refer to the early period of the fourteenth century BC, when relations among the rulers of the city-states in the territory of Canaan were characterized by intense conflicts and hostilities. The letters mention three rulers of Gezer: Milkilu, Ba'lu-dānu, and Yapahu, unique case in the Amarna Letters. The letters not only show evidence of the growing conflicts in the region, but also testify abundant trade activities between Gezer and Egypt, and the sudden fall of Egyptian dominance in the region of Canaan.

Key words: Amarna Letters, Egypt, Gezer, Trade, 'apîru

\section{RESUMEN}

En este artículo abordaremos las cartas de Amarna 267-272, 293, 298-300, 369 y 378, que contienen las correspondencias de los gobernantes de la Ciudad-Estado de Gezer para el rey de Egipto. Ellas se refieren al período inicial del siglo XIV a.C., cuando las relaciones entre los gobernantes de las ciudades-estados, en el territorio de Canaan estaban marcadas por intensos conflictos y hostilidades. Las cartas mencionan tres gobernantes de Gezer: Milkilu, Ba'lu-dānu y Yapahu, caso único en entre la correspondencia de Amarna. Además de evidenciar los conflictos crecientes en la región, las cartas también dan testimonio de la abundante actividad comercial entre Gezer y Egipto y el rápido debilitamiento del dominio egipcio en Canaan.

Palabras clave: Cartas de Amarna, Egipto, Gezer, Comercio, 'apîru
\end{abstract}

* Este artigo é parte da produção de pesquisa realizada durante o ano de 2017 pelo Grupo de Pesquisa "Arqueologia do Antigo Oriente Próximo", da Universidade Metodista de São Paulo - Reg. no CNPq $\mathrm{N}^{\circ} 4338921870858325$. 


\section{Introdução}

O conteúdo das correspondências dirigidas ao rei do Egito (Amenhotep III 1389-1349 a.C., e/ou Amenhotep IV ou Akhenaton 1349-1333 a.C.) é de conflitos, acusações, defesas e denúncias, o que dificulta uma leitura mais assertiva dos relatos, pois sempre persistem as dúvidas, algo muito comum em escritos literários, e mais especialmente em escritos antigos. Contudo, as cartas nos apresentam uma riqueza de dados geográficos, além de uma constante e admirável comunicação entre os governantes das cidades que, em tempos tão remotos, causa grande admiração.

Por esses motivos, as cartas de Amarna sempre foram consideradas testemunhos fundamentais para a compreensão, tanto da presença do império egípcio na região de Canaã, como, também, para o conhecimento da configuração político-social da região. Sob estas duas perspectivas, tentaremos fazer a leitura do conjunto de cartas referentes aos governadores de Gezer. Em primeiro lugar, apresentamos uma tradução das cartas, depois tentaremos compreender quem eram seus governantes para, posteriormente, apresentar algumas anotações a respeito do conteúdo das tabuletas.

\section{Tradução das Cartas}

A tradução foi realizada a partir das versões em inglês das tabuletas (MORAN 1992; RAINEY 2015), priorizando as opções do texto crítico de Rainey (2015). Apresentamos uma tradução corrida, juntamente com a estrutura, proveniência da tabuleta e um curto comentário relacionado ao conteúdo.

\section{EA 267}

\section{Tradução}

(1-8) Dize [pa]ra o rei, meu senhor, meu deus, meu deus sol, a mensagem de Milkilu seu servo, a sujeira sob seus pés: aos pés do rei, meu senhor, meu deus, meu deus sol, sete vezes (e) sete vezes eu tenho me prostrado.

(9-14) Quanto à palavra que o rei, meu senhor, meu deus, meu deus sol, enviou pa[ra] mim, agora eu estou preparando para o r[e]i, meu senhor, o deus sol do céu.

(15-20) E pode o rei, meu senhor, meu deus, meu deus sol, ser informado que está bem o lugar do rei, meu senhor, que está sob meu cargo.

\section{Estrutura}

Para definir a estrutura de cada uma das cartas, assumiremos os critérios de categorização elaborados por Jana Mynárová (2007, p.106s). Esta autora estabeleceu alguns modelos de estruturas para o conjunto das cartas de Amarna. Seguindo suas análises, propomos a seguinte estrutura: 
Introdução (1-8)

Ordem para redigir o texto e identificação do remetente

Fórmula de submissão.

Conteúdo (9-14)

Expressão de lealdade e execução da ordem do faraó

Conclusão (15-20)

Relatório: a terra está tranqüila

\section{Proveniência}

A análise petrográfica de E $A 267$ mostra que a argila da tabuleta deve ter vindo das proximidades do Tel Gezer, o que permite afirmar que a carta teria sido preparada e enviada desde Gezer (GOREN \& FINKELSTEIN \& NA'AMAN, 2004, p.271).

\section{Comentário}

A tradução apresentada por William L. Moran é muito similar, sem oferecer variantes consideráveis. Aliás, a conservação do texto é relativamente boa, motivo pelo qual não foram necessárias muitas reconstruções.

Duas cartas anteriores (EA 249-250: Mensagens de Ba'lu-meher), nos oferecem várias informações sobre Milkilu. Em primeiro lugar, o remetente relata ao rei que seus homens estão a serviço do governante de Gezer; também nos diz que Milkilu é genro do Tagi e, finalmente, que há uma aliança entre ele e os filhos de Labayu, que é chamado de "traidor" do rei.

Já na tabuleta 267, Milkilu descreve a tranquilidade reinante no território, informação que contradiz as duas cartas anteriormente referidas. Esta situação dificulta muito a possibilidade de datar a carta, pois, além da própria tabuleta não oferecer nenhuma data - algo muito comum entre todo o conteúdo epistolar de Amarna, já que apenas quatro recebem datas específicas: EA 11, 23, 27 e 254 (cf. MYNÁROVÁ 2011, p.123) -, descreve um cenário de tranquilidade, o que supõe um momento anterior às revoltas promovidas por Labayu e antes de Milkilu perder a posse das terras para Yahtiru (EA 296-298).

\section{EA 268}

\section{Tradução}

(1-7) Dize [para] o rei, meu [sen]hor, [meu] de[us], meu [deus sol], [a mens]agem de Milkilu, seu servo, [a sujei]ra sob seus pés: aos pés do rei, meu senhor, meu deus, meu deus sol, sete vezes (e) sete vezes, eu tenho me prostrado.

(8-10) Pode [o rei], meu [senhor], ser informado que [a cidade] do rei, meu senhor, que [ele confiou] para [minha] autori[dade], está bem. 
(11-14) [E] a coisa [que o rei], meu [senhor, meu deus, meu deus sol, enviou, eu a preparei para el]e.

(15-21) [E agora,] eu [tenho enviado sob a autorida[de] de Hay[a]: quarenta e seis servas e cinco servos e cinco ašîrûma para o rei, meu senhor.

\section{Estrutura}

\section{Introdução (1-7)}

Ordem para redigir o texto e identificação do remetente

Fórmula de submissão.

Conteúdo (8-21)

Relatório sobre a situação da cidade, afirmando que a cidade se encontra bem.

Confirmação do cumprimento das ordens enviadas pelo faraó.

Envio sobre autoridade de Haya de servas, servos e cinco ašîrûma.

\section{Proveniência}

A análise petrográfica de EA 268 é similar à da carta 267 (GOREN \& FINKELSTEIN \& NA'AMAN, 2004, p.272). Segundo anotação destes autores, a tabuleta pode ter sido secada a uma temperatura maior do que a habitual.

\section{Comentário}

A tradução apresentada por William L. Moran é similar, porém difere no número de pessoas enviadas para o rei: "Envio no cuidado de Haya 46 mulheres, 3 e 5 mulheres, 4 e 5 altruma para o rei, meu senhor". As "altruma" são consideradas como escravas mulheres e copeiras, porém o autor diz que sua função não era muito clara.

Em comparação com a $E A$ 267, esta carta já precisou de maiores intervenções na reconstrução hipotética do seu conteúdo. Em primeiro lugar, encontramos as já conhecidas fórmulas de saudação e submissão (fórmula muito comum nas cartas, como por exemplo, EA 243, 246, 247, 301, 302, 306, assim como o remetente se considerar "a sujeira sob os pés do rei", EA 248). Em seguida, Milkilu fala sobre o estado da cidade, afirmando que está tudo bem.

Após o relatório, chama a atenção a referência ao envio de servas (nomeadas em primeiro lugar!), servos e ašîrûma. Pelo contexto, pode-se inferir que se trata de pessoas para o serviço do rei e, completando com a informação que encontramos na tabuleta $E A 369$, é possível pensar que havia um fluxo constante na comercialização de pessoas. Nesse comércio de pessoas, impressiona também o elevado número de mulheres (46) em comparação com os 
servos e ašîrûmas (5). Na carta $E A$ 280, encontramos, também, referência ao envio de 21 meninas e 80 prisioneiros como presentes para o rei.

Menciona-se, também, outra personagem: Haya. Pelo contexto, parece ser um emissário do rei do Egito. No entanto, apesar de todas essas informações, ficamos sem saber se o envio das servas, dos servos e das ašîrûmas seria fruto do comércio entre os governantes das cidades e o rei do Egito ou se essas pessoas formam parte do pagamento de tributo. Ao final da carta, é notável a ausência de uma fórmula de encerramento.

\section{EA 269}

Tradução

(1-8) Dize [pa]ra o rei, meu senhor, meu deus, me deus sol, a mensagem de Milkilu,seu servo, a sujeira de seus pés: aos pés do rei, meu senhor, meu deus, meu deus sol, sete vezes (e) sete vezes eu tenho me prostrado.

(9-17) Eu ouvi o que o rei, meu senhor, tem escrito para mim. Assim que o rei, meu senhor, envie tropas regulares para seu servo e que possa o rei, me senhor, enviar mirra para a cura.

\section{Estrutura}

Introdução (1-8)

Ordem para redigir o texto e identificação do remetente

Fórmula de submissão.

Conteúdo (9-17)

Confirmação do recebimento da mensagem enviada pelo faraó. Solicitação de envio de tropas, junto com remédios

\section{Proveniência}

A análise petrográfica de EA 269 é similar à da carta 267 (GOREN \& FINKELSTEIN \& NA'AMAN, 2004, p.272), tendo sido preparada e enviada desde Gezer.

\section{Comentário}

A tradução de William L. Moran é bastante similar. Chama a atenção o bom estado da $E A 269$, sem requerer muitas conjecturas para reconstruir o seu conteúdo.

Além da já habitual fórmula de saudação e submissão, não temos mais semelhanças com as cartas anteriores. Após reafirmar ter recebido a mensagem do rei do Egito, Milkilu faz um apelo para o envio de tropas, o que sugere a presença de conflitos dentro de seu território. Essa informação é confirmada pelo pedido de mirra, utilizada no cuidado dos feridos. 
A mirra (commiphora myrrba), também conhecida como mirra-arábica, mirra-verdadeira ou incenso, é uma planta medicinal oriunda da África e Arábia. A mirra é um arbusto espinhoso da família Chenopodiaceae que nasce principalmente no nordeste africano e no interior da Arábia, podendo chegar até três metros de altura. Tem usos terapêuticos e antissépticos.

Esta carta nos apresenta, então, um período de transição na cidade-estado de Gezer, que teria passado de um momento de relativa tranquilidade - como o próprio Milkilu tinha afirmado em EA 267 e EA 268 - para momentos de tensão e conflito.

\section{EA 270}

\section{Tradução}

(1-8) Dize para o rei, meu senhor, meu deus, meu deus sol, a mensagem de Milkilu, seu servo, a sujeira em seus pés: aos pés do rei, meu senhor, sete vezes (e) sete vezes, eu tenho me prostrado.

(9-13) Possa o rei, meu senhor, ser informado dos atos que Yanhamu está fazendo para mim, desde a minha vinda diante da presença do rei, meu senhor,

(14-21) que ele ped[indo] três mil (siclos de) prata de minha mão e dizendo-me, "dê-me sua esposa e seus filhos ou então eu vou ferir (você)".

(21-29) Assim que o rei for informado deste ato e possa enviar o rei, meu senhor, carruagens e possa me levar para sua presença para que eu não pereça.

\section{Estrutura}

Introdução (1-8)

Ordem para redigir o texto e identificação do remetente

Fórmula de submissão.

Conteúdo (9-21)

Relatório sobre as ações de Yanhamu, contra Milkilu.

Referência a uma visita de Milkilu ao rei.

Conclusão (21-29)

Pedido de ajuda e asilo: envie tropas para me levar para sua presença!

\section{Proveniencia}

A análise petrográfica de EA 270 é similar à da carta 267 (GOREN \& FINKELSTEIN \& NA'AMAN, 2004, p.272), tendo sido preparada e enviada desde Gezer.

\section{Comentário}

William L. Moran intitula a carta como a "extorsão", fazendo referência à situação que está sofrendo Milkilu por parte de Yanhamu. A quantidade que ele pede de Milkilu é diferente (dois mil siclos), em comparação com a tradu- 
ção de Anson Rainey, e a ameaça contra ele é de morte, e não de ferimento. Apesar destes pormenores, o conteúdo da carta é bastante compreensível.

Em relação com as cartas anteriores, a situação de conflito nas terras de Gezer parece estar em aumento. Enquanto, nas duas primeiras (EA 267268), o governador reporta tranquilidade na terra, em EA 269 já começa mencionando o conflito e, como ápice, a EA 270 descreve a extorsão de Yanhamu e as ameaças de morte para Milkilu.

Por que Yanhamu pede para Milkilu entregar sua mulher e seus filhos? Talvez porque eles formavam parte do espólio cobrado pelo vencedor ou, também, como uma maneira de expressar seu poder: deixar Milkilu sem família pode ser uma forma de dizer que ele já não tem poder e não consegue nem garantir a segurança para sua família! Também pode expressar uma forma de "controlar" os possíveis sucessores do governante. Ao final da carta, a situação parece ser tão angustiante que o governador não cogita ficar para resgatar seu território, mas ser levado para longe, para o lado do rei. Fica a dúvida se a família fugiria junto com ele ou ficaria em mãos de Yanhamu...

\section{EA 271}

\section{Tradução}

(1-8) Dize para o rei, meu senhor, meu deus, meu deus sol, a mensagem de Milkili, seu servo, a sujeira sob seus pés: aos pés do rei, meu senhor, meu deus, meu deus sol, sete vezes e sete vezes tenho caído.

(9-21) Possa o rei, meu senhor, ser informado que a hostilidade é forte contra mim e contra Shuwardata, assim possa o rei, meu senhor, entregar sua terra nas mãos dos homens 'apîru. Mas se não, envie o rei, meu senhor, carruagens para nos levar para que os nossos próprios servos não nos firam.

(22-27) E, além disso, pergunte o rei, meu senhor, para [Y]anhamu, seu servo, ao respeito do que está sendo feito em sua terra.

\section{Estrutura}

Introdução (1-8)

Ordem para redigir o texto e identificação do remetente

Fórmula de submissão.

Conteúdo (9-21)

Relatório sobre as hostilidades contra Milkilu e Shuwardata.

Referência à presença dos 'apîru.

Pedido de auxílio

Conclusão (22-27)

Referência a Yanhamu, como fonte de informações. 


\section{Proveniência}

A análise petrográfica de EA 271 é similar à da carta 267 (GOREN \& FINKELSTEIN \& NA'AMAN, 2004, p.272), tendo sido preparada e enviada desde Gezer.

\section{Comentário}

No seu estilo interpretativo, William L. Moran denomina a carta como "O poder dos 'apîru". A carta contém referências aos conflitos presentes: em primeiro lugar, aparece a designação de Shuwardata e Milkilu como as vítimas da hostilidade. Na carta EA 290, Shuwardata é apresentado como o comandante de Gath (também em EA 278-279; 281-284; 366) e em aliança com Milkilu. Nessas tabuletas, eles estão doando terras pertencentes ao rei, no território de Jerusalém, aos 'apîru. Situação diferente da descrita nesta carta, na qual, em termos apelativos, o governante de Gezer pressiona o rei para que envie carruagens para a defesa deles dois, ou, caso contrário, a terra cairá nas mãos dos 'apîru.

É importante destacar que a ameaça de ferimento provém dos “próprios servos" de Milkilu, insinuando-se, assim, a existência de uma aliança entre os servos e os 'apîru.

Finalmente, a carta sugere um interrogatório de Yanhamu por parte do rei, como se ele tivesse sido convocado para tal finalidade, após o conflito descrito na EA 270. Fica, porém a dúvida, a respeito de Yanhamu, pois não sabemos se ele é aliado de Milkilu ou se, como foi mencionado na carta $E A$ 270, ele é inimigo e está extorquindo o governante de Gezer.

Também ficamos sem saber a origem dos 'apîrus aqui mencionados, pois a carta não diz de onde eles provêm, nem qual é seu destino. No entanto, a tabuleta deixa entrever uma aliança tácita entre os 'apîrus e os servos de Milkilu, indicados no escrito como os causadores dos ferimentos. Quem eram esses "servos"? Trata-se de pessoal próximo ao palácio do governante? São os comerciantes que orbitam em torno de Milkilu? São integrantes de seu exército? São agricultores que moravam nas redondezas da cidade de Gezer? São perguntas que pairam em torno da tabuleta e para as quais ela não oferece elementos suficientes para formular uma resposta.

\section{EA 272}

(1-7) [Pa]ra o rei, [meu senhor, meu deus], meu deus sol, [dize]: A mensagem de Ba'lu-dāni, [seu servo], a sujeira de [seus] pés: [O]que de ao 'pé' do rei, meu senhor, meu deus, meu deus sol, sete vezes (e) sete vezes eu tenho me prostrado.

(8-9) Um leal servo d [o rei,] meu senhor, eu sou.

(10-17) Possa o rei, meu senhor, [ser] avisado [que] os governantes da cidade [que foram] no ponto forte tem finalizado [e toda] a terra do rei, meu senhor, caiu para os homens 'apîru. 
(18-25) Caso possa o rei, meu senhor, pergunte a seu emissário ao respeito do que está acontecendo na terra do r[ei], meu senhor, e possa meu rei, meu senhor, enviar as tropas regulares para mim.

\section{Estrutura}

Introdução (1-7)

Ordem para redigir o texto e identificação do remetente Fórmula de submissão.

Conteúdo (8-17)

Reafirma a lealdade de Ba'lu-dāni

Relatório sobre a queda da cidade nas mãos dos 'apîru. Conclusão (18-25)

Recomendação para consultar o emissário do rei, ao respeito da situação da terra.

Pedido de tropas.

\section{Proveniência}

Goren e Finkelstein confirmam a hipótese de Knudtzon (1915:1323, n.1), segundo a qual esta tabuleta teria sido fabricada em Gezer (GOREN \& FINKELSTEIN \& NA'AMAN, 2004, p. 275).

\section{Comentário}

William L. Moran denomina a carta "Atividade dos 'Apiru", dando continuidade às cartas anteriores, onde foram descritos a presença e o avanço dos 'apîru no território de Gezer.

Naaman (2001b) propôs que o nome da cidade seria a Anaharath bíblica, identificada com Tel Rekhesh, em Naúal Tavor. De acordo com esta sugestão, o autor da carta seria um aliado de Milkilu de Gezer, Bayadi (Ba 'lu-dāni), possivelmente seu antecessor, aliado dos Labayu de Siquém. Ele deve ter vindo a Gezer enquanto ia de caminho para Gaza, ou para negociar com Milkilu, e naquela ocasião pediu ao escriba de Milkilu para escrever uma carta ao rei do Egito em seu nome (GOREN \& FINKELSTEIN \& NA'AMAN, 2004, p.275).

É importante destacar a mudança do remetente, sendo agora identificado como Ba'lu-dāni. O que não fica claro na carta é se esta personagem é antecessora ou sucessora de Milkilu. Mesmo assim, é significativo que três governantes de Gezer sejam conhecidos: Milkilu, Yapahu e Ba'lu-dāni, pois a menção de três governantes para uma mesma cidade é algo sem paralelo nas cartas de Amarna. 
Após as saudações protocolares e a afirmação da lealdade, a carta informa sobre o avanço dos 'apîru, que agora controlam a cidade, ratificando o processo descrito na $E A$ 271. Ainda assim, o remetente insinua que o envio de tropas por parte do rei pode modificar e normalizar a situação.

Ao final da carta, é enigmática a menção ao emissário do rei: quem é este sujeito? Qual é sua função na situação que vive a cidade-estado de Gezer?

\section{EA 293}

\section{Tradução}

(1-7) Di[ze para o rei], meu [senhor], [m]eu d[eu]s, meu deus [so]l; a men[sa]gem de Ba ludāni, [seu] servo, a sujeira embaixo de seus pés: [ao]s pés do rei, meu senhor, meu deus, meu deus sol, sete vezes (e) [sete] vezes eu tenho me prostrado.

(8-11) [Eu] ouvi a palavra que o rei, meu senhor, escreveu para seu servo, "Guarda os lugares que o rei deixou a teu cargo".

(12-17) Agora eu estou guardando dia e noite porque os inimigos do r[e]i, meu senhor, são os homens 'apîru, mas um servo leal é seu emissário.

(17-23) Agora [...] onde quer [que ele] chegue [...] com eles [para o rei] meu senhor [até que o rei meu senhor] chegue.

\section{Estrutura}

Introdução (1-7)

Ordem para redigir o texto e identificação do remetente

Fórmula de submissão.

Conteúdo (8-17)

Reafirma a recepção da mensagem do rei, solicitando a guarda dos lugares.

Execução da ordem

Identificação dos 'apîru como os inimigos do rei

\section{Conclusão (17-23)}

Parece um pedido para que o rei se apresse a chegar com suas tropas.

\section{Proveniência}

A análise petrográfica de EA 293 é similar à da carta 267 (GOREN \& FINKELSTEIN \& NA'AMAN, 2004, p.273) e teria sido escrita em Gezer.

\section{Comentário}

Esta segunda carta de Ba'lu-dāni parece uma resposta ao rei a uma ordem anterior, enviada por meio de um emissário. Pelo conteúdo, este emissário já teria constatado o avanço dos 'apîru no território e, assim, seria fonte confiável para ser consultada pelo rei. 
O governador da cidade considera-se não como proprietário da terra, mas como "encarregado" e representante do rei, com a missão de "cuidar da terra do rei". A referência a "guardar dia e noite" pode indicar a situação de risco iminente, que exige uma vigilância constante. Também é clara a identificação dos 'apîru como os inimigos do rei, aqueles que põem em risco a segurança da cidade.

Ao final da tabuleta, aparece um pedido: que o rei apresse o envio das tropas para combater os inimigos do rei, os 'apîrus.

\section{EA 298}

Tradução

(1-14) [Pa]ra o rei, meu senhor, meu deus, meu [deus sol], o deus sol do céu, a mensagem de Yapa'i, o governante da cidade de Gezer, seu servo, a sujeira de seus pés, o palafreneiro dos seus cavalos: aos pés do rei, meu senhor, o sol do céu, sete vezes e sete vezes eu realmente tenho me prostrado, eu mesmo de estômago e de costas.

(14-17) Tudo o que o rei, meu senhor dize para mim, eu tenho ouvido muito atenta[mente]. (18-19) O servo do rei eu sou, e a sujeira dos seus p[és].

(20-29) Que o rei, meu senhor, seja informado que meu irmão mais novo tornou-se hostil a mim e ele tem entrado na cidade de Mô' hazi e ele tem com[prome]tido para os 'apîru. E agora ele está fazendo guerra contra mim.

(30-33) Por tanto, tome conselho ao respeito de sua terra. Possa meu senhor escrever para seu emissário sobre este assun[to].

\section{Estrutura}

Introdução (1-14)

Ordem para redigir o texto e identificação do remetente, Yapa'i (Yapahu)

Fórmula de submissão.

Conteúdo (14-29)

Reafirma a recepção atenta da mensagem do rei e sua submissão.

Relatório sobre as hostilidades do irmão mais novo e sua aliança com os 'apîrus.

Conclusão (30-33)

Pedido de ajuda para que o rei salve sua terra.

\section{Proveniência}

A análise petrográfica de EA 298 mostrou que esta é uma das poucas cartas que foram escritas no noroeste do Neguev, assim como as tabuletas EA 299-300. As matérias-primas específicas identificadas apontam para a faixa entre Raphia e Ashkelon. A única explicação viável é que EA 298 tenha sido escrita em Gaza, o principal centro administrativo egípcio no sul de Canaã (GOREN \& FINKELSTEIN \& NA'AMAN, 2004, p.274). 


\section{Comentário}

A carta está em bom estado de conservação, motivo pelo qual não são necessárias muitas restaurações.

$\mathrm{Na}$ primeira parte, Yapahu se apresenta com fórmulas exageradas de submissão: "aquele que é o palafreneiro dos seus cavalos e que deita de estômago e de costas". A expressão "parafreneiro dos seus cavalos" também aparece em outras cartas (EA 299, EA 300, EA 303, EA 304, EA 305, EA 308), assim como o "deitar de estômago e de costas". Como explicar o uso destas expressões? Talvez seja porque a situação em que se encontra o remetente da carta era desesperadora, diante do avanço de aliança de seu irmão com os 'apîru, ou também porque ele deseja deixar claro para o rei que ele não forma parte dessa coalizão anti-Egito. "Deitar de costas e de estômago", além de expressar a total submissão ao rei do Egito, também pode ser expressão de total confiança, comunicando, assim, a espera incondicional da ajuda do rei egípcio.

O conteúdo da carta permite inferir a existência de uma coalizão contra o Egito, representada aqui pelo irmão caçula de Yapahu e os 'apîru, mas que, sem dúvida, incluía outros governantes da região. Diante dessa situação, também temos uma coalizão pró-Egito, talvez representada aqui pela cidade de Mô'hazi e pelo próprio Yapahu. No entanto, a carta deixa claro que a cidade de Mô'hazi já está sob controle do irmão caçula e dos 'apîru, sujeitos responsáveis, também, pela perda de todas as provisões, segundo afirma o começo da carta.

\section{EA 299}

\section{Tradução}

(1-11) [Pa]ra o rei, meu senhor, meu deus, meu deus sol, o deus sol do céu, a mensagem de Yapa i, o governante da cidade de Gezer, seu servo, a sujeira de seus pés, o palafreneiro dos seus cavalos: aos pés do rei, meu senhor, meu deus, meu deus sol, o deus sol do céu, sete vezes, sete vezes eu verdadeiramente tenho me prostrado, de estômago e de costas. (12-14) Eu tenho atendido com muito cuidado às palavras do emissário do rei, meu senhor. (15-17) Possa, assim, o rei meu senhor, o deus sol do céu, tomar conselho ao respeito de sua terra.

(17-26) Ora, os homens 'apîru são mais fortes do que nós, assim, possa o rei meu senhor, enviar sua mão para mim e possa me livrar da mão dos homens 'apîru para que os homens não nos limpem.

\section{Estrutura}

Introdução (1-11)

Ordem para redigir o texto e identificação do remetente, Yapa'i

Fórmula de submissão, igual da EA 298. 
Conteúdo (12-14)

Reafirma a recepção atenta da mensagem do emissário do rei.

Conclusão (30-33)

Reconhecimento do poderio dos 'apîru e pedido de ajuda.

\section{Proveniência}

A análise petrográfica de EA 299 é similar à da carta 298 (GOREN \& FINKELSTEIN \& NA'AMAN, 2004, p.274), o que permite afirmar que a carta teria sido escrita em Gaza.

\section{Comentário}

É impressionante a semelhança existente entre EA 298 e 299 no cabeçalho da carta. Além de se tratar do mesmo emissor (Yapahu), identificado como governante da cidade de Gezer, a carta repete as fórmulas de submissão, identificando-se como o palafreneiro de seus cavalos e aquele que deita de estômago e de costas.

William L. Moran intitula a carta como "Um pedido de ajuda", fazendo referência às últimas linhas da carta, onde Yapahu clama pela ajuda do rei e descreve a violência dos 'apîrus como "limpeza". Aliás, eles são apresentados como "mais fortes do que nós", ficando a dúvida a respeito dos sujeitos implícitos nesse "nós", repetido na referência à violência dos 'apîrus: "para que eles não nos limpem”. Pelo contexto da carta anterior (EA 298), pode-se pensar que o governante se refira a ele e ao governante de Mô' hazi.

\section{EA 300}

\section{Tradução}

(1-10) D[iz]e [para o rei,] me [se]nhor, [meu de]us, [meu deus sol], o [deus sol] do céu; a mensagem de Yapa'i, governador [d]a [cidade de] Gezer, seu servo e a sujeira embaixo de seus pés, o palafreneiro dos seus $\mathrm{Ca}[\mathrm{va}$ los: a[os] pés do [rei, me]u senhor sete vezes e sete vezes eu tenho me prostrado.

(10-14) Possa o rei, meu senhor, ser informado a respeito de seu servo. Perdidas são as provis[ões] de minha terra e agora não tenho nada.

(15-22) Assim possa o rei enviar suas tropas. Elas podem restaurar minhas cidades e eu verdadeiramente servirei o rei, meu senhor, como meu pai e [meus] antepassados.

(23-28) Além disso, eu estou constantemente obedecendo as palavras do rei, meu senhor, e eu estou obedecendo as palavras de Maya, o emissário do rei, meu senhor, [o deus sol] do céu, o fi[lho] do deus sol.

\section{Estrutura}

Introdução (1-10)

Ordem para redigir o texto e identificação do remetente, Yapaci

Fórmula de submissão, quase igual da EA 298. 
Conteúdo (10-22)

Relatório sobre a perda das provisões.

Pedido de ajuda para restaurar as terras e promessa de submissão.

Conclusão (23-28)

Reafirma a obediência às ordens do rei, enviadas por meio de Maya.

\section{Proveniência}

A análise petrográfica de EA 300 é similar à da carta 298 (GOREN \& FINKELSTEIN \& NA'AMAN, 2004, p.274), o que permite afirmar que a carta teria sido escrita em Gaza.

\section{Comentário}

Encontramos semelhança existente entre EA 298 e 300 no cabeçalho da carta. Além de se tratar do mesmo emissor (Yapahu), identificado como governante da cidade de Gezer, a carta repete as fórmulas de submissão, identificando-se como "o palafreneiro dos cavalos", porém, falta a última parte ("aquele que deita de estômago e de costas").

Outra diferença significativa em relação à carta anterior está no fato consumado do domínio dos 'apîrus sobre a terra, expresso na perda das provisões e no pedido de envio de tropas para restaurar a terra. Isto significaria o avanço triunfal da coalizão anti-egípcia e a derrota dos governadores pró-Egito. Ainda assim, o governante comunica seu desejo de continuar leal ao rei, caso este consiga reverter a situação e lhe devolver suas terras.

Finalmente, também é importante destacar a menção a Maya, emissário do rei, funcionário que mantinha a comunicação entre os governos locais e o rei do Egito.

\section{EA 369}

\section{Tradução}

(1-2) Para Milkilu, governador de Gezer, assim o rei:

(2-14) Agora, esta tabuleta foi enviada para você para dizer a você: agora tenho enviado Hanya, <comandante de> do exército regular, com tudo para a aquisição de formosas mulheres copeiras, prata, ouro, roupas de linho, pedras de cornalina, todo (tipo de) pedras preciosas, cadeira de ébano, da mesma forma, tudo de excelente qualidade. Total: cento e sessenta diban. Total: quarenta mulheres copeiras.

Quarenta (siclos de) prata é o preço de uma mulher copeira.

(15-23) Então, envie mulheres copeiras muito bonitas, em que não há malícia entre elas, de modo que o rei diga para você, "Isto é excelente, conforme com a solicitação que ele enviou para você".

(24-27) E possa ser você informado que o rei está saudável, como deus sol, seu exército, suas carruagens, seus cavalos todos está muito bem.

(28-32) Agora Amon colocou a terra superior, a terra inferior (de) vinda do deus sol (para) a entrada do deus sol debaixo dos pés do rei. 
Introdução (1-2)

Endereçamento: para Milkilu

Conteúdo (2-23)

Aquisição de formosas mulheres

Caracterização das mulheres

Conclusão (24-32)

Mensagem de bem-estar do rei. Referência a Amon.

\section{Proveniência}

A análise petrográfica de EA 369 (GOREN \& FINKELSTEIN \& NA'AMAN, 2004, p.84) mostra sua proveniência egípcia, tratando-se de cartas de estilo formal e próprio de textos oficiais. Possivelmente, pode ter sido escrita em Assíria ou Mitanni.

\section{Comentário}

A carta $E A 369$ forma parte do conjunto por sua referência a Milkilu, mostrando, assim, uma contínua troca de correspondência e mercadorias entre a cidade de Gezer - o que destaca ainda mais sua importância na região - e o rei do Egito, motivo pelo qual, na tradução de William L. Moran, ela é chamada de carta "do faraó para o vassalo".

Nesta tabuleta, chama a atenção a identificação do "enviado" do rei (Hanya), comandante do exército regular, o que implicaria que as funções de diplomacia eram executadas também pelos militares. Não só isso: eles seriam os responsáveis pelas transações comerciais e, neste caso, pela compra de mulheres formosas.

A carta descreve os materiais utilizados para a troca: prata, ouro, roupas de linho, pedras de cornalina, pedras preciosas, cadeira de ébano, da mesma forma, tudo de excelente qualidade. Esses materiais teriam um valor total equivalente a 160 diban. Segundo Moran, um diban equivaleria a 91 gramas de prata. Também devemos destacar o preço determinado por cada mulher (quarenta siclos de prata), o que pode significar que era comum a comercialização das mulheres, a ponto de se ter já estabelecida uma tabela mais ou menos fixa.

$\mathrm{Na}$ compra das mulheres, destaca-se a insistência em que sejam "copeiras muito bonitas, em que não há malícia", de modo que o rei possa dizer que "Isto é excelente, conforme com sua solicitação".

$\mathrm{Na}$ conclusão da tabuleta, temos a referência a Amon, como aquele que "colocou a terra superior, a terra inferior (de) vinda do deus sol (para) a entrada 
do deus sol debaixo dos pés do rei" parece indicar uma redação anterior para esta carta, um período no qual a terra estava em tranquilidade (MORAN 1992, p.xxxvii). Neste sentido, esta tabuleta parece ter sido escrita por Amenhotep III, pois glorifica Amon, não Aton, pela conquista do Alto Egito.

\section{EA 378}

Tradução

(1-10) [Para o re[i], meu [senhor], meu deus, [meu deus sol], o deus sol do céu, mensagem de Ya[pa'i], governador da cidade de Gezer, [seu servo], a sujeira de [seus] pés: aos pés do rei, meu senhor, meu deus, meu deus sol, o deus sol [do] céu, sete vezes e sete vezes eu verdadeiramente tenho me prostrado, de estômago e de costas.

(10-17) Agora eu estou guardando o lugar do rei, meu senhor, o deus sol do céu, que está a meu cargo, e quanto a todo o que o rei, meu senhor, tem escrito para mim, eu estou realmente fazendo tudo.

(18-26) [E o qu]e eu sou, um cão, [e o qu]e é minha casa, [e o qu]e é minha cidade, [e o qu] e é todo o que me pertence, que eu não deveria atender continuamente a todas as palavras do rei, meu senhor, o deus sol do céu?

\section{Estrutura}

Introdução (1-10)

Ordem para redigir o texto e identificação do remetente, Yapa'i Conteúdo (10-17)

Identificação de sua missão: guardar o lugar do rei

Conclusão (18-26)

Defesa retórica de sua lealdade, a serviço do rei como um cão

\section{Proveniência}

A análise petrográfica de $E A 378$ mostra uma origem similar à tabuleta 298 (GOREN \& FINKELSTEIN \& NA'AMAN, 2004, p.275), o que permite afirmar que esta tabuleta teria sido enviada desde Gaza.

\section{Comentário}

A introdução é similar à da carta EA 298, sendo um pouco menos solene. Yupahu se identifica como governador da cidade de Gezer. Como em outras cartas (EA 298-300), encontramos a mesma fórmula de submissão (deitar de estômago e de costas), mas falta a identificação como "palafreneiro do rei".

O conteúdo da carta confirma a disposição do governador de guardar e proteger tudo quanto o rei deixou sob sua guarda, retomando, no final da EA 378, a total submissão aos desígnios do rei, confirmando que ele só é um "guardador" das coisas do rei. Mas, assim como já tinha acontecido com Ba'lu-dāni, não sabemos se Yapahu governou a cidade antes que Milkilu. 
A partir das traduções apresentadas, vamos fazer um balanço das informações que as tabuletas nos oferecem.

\section{Os governadores de Gezer}

O conjunto de tabuletas que acabamos de traduzir nos apresenta três governantes na cidade-estado de Gezer:

- Milkilu, (EA 267-271; EA 369)

- Ba'lu-dānu, (EA 272; EA 293)

- Yapahu, (EA 298-300; EA 378)

As tabuletas, porém, não permitem afirmar que sejam membros de uma mesma família. Sem dúvida, é importante destacar que estamos diante um caso único na correspondência de Amarna, pois somente da cidade de Gezer as cartas nos informam os nomes de três governantes.

Com relação a Milkilu, as informações são mais abundantes: pelas cartas EA 249-250, sabemos que ele era o governante de Gezer; era genro de Tagi - que governava em Ginti-Kirmil -; e que tinha feito uma aliança com os filhos de Labayu. A carta também informa que os homens de Ba'lu-Meher estavam a serviço de Milkilu, o que permite inferir que ele controlava a região.

Já a tabuleta $E A 268$ informa-nos ao respeito do envio de quarenta e seis servas e cinco servos e cinco ašrîuma para o rei, meu senhor. No entanto, não nos diz se o envio dessas pessoas forma parte do tributo devido pelo governante de Gezer ao rei do Egito ou se são presentes enviados para o rei como expressão da gratidão e submissão ou, finalmente, se são produtos comerciais. Contudo, e segundo a EA 369, onde o rei pede para Milkilu adquirir formosas mulheres copeiras, fica evidente um relacionamento comercial constante entre Egito e Gezer.

Segundo as cartas E $A 270$ e 271, também eram frequentes as alianças entre governantes locais. No caso, trata-se da aliança com Yanhamu e com Shuwardata. No entanto, fica a impressão que entre eles também existiam muitos conflitos.

São mais obscuras as informações que temos sobre Ba'lu-dānu. Só duas cartas se referem a ele (EA 272 e 293). Em primeiro lugar, ele se identifica como servo encarregado pelo rei para cuidar de suas terras. Além disso, as duas cartas mencionam a presença dos 'apîrus no território, motivo pelo qual, nas duas cartas, Ba'lu-dānu solicita a ajuda do rei para retomar o controle da terra.

As cartas sobre Yapahu, (EA 298-300; EA 378) também informam sobre a presença dos 'apîrus nas terras do rei, assim como sobre a perda das provisões. $\mathrm{Na} E A$ 298, Yapahu fala da aliança de seu irmão com os 'apîrus, 
indicando, assim, a existência de uma aliança anti-Egito, fato ratificado pelas informações que encontramos nas tabuletas EA 299 e 300. Já a carta EA 378 parece anterior aos acontecimentos descritos nas EA 298-300, pois Yapahu ainda está guardando, como um cão, as terras do rei.

De acordo com estas informações, podemos deduzir que Gezer era uma cidade importante na região de Canaã:



Como era a relação do Egito com estas cidades? Segundo Mario Liverani, "o período amarniano foi geralmente considerado como um momento de decadência do domínio egípcio na Ásia, mas, ainda assim, o controle egípcio continuava a ser exercitado em suas formas habituais" (LIVERANI, 2016, p.467). Isto significa que não podemos considerar o domínio egípcio nos parâmetros de um controle político-militar, econômico e social da região. É mais factível compreender a presença egípcia em termos de alianças estratégicas com fins comerciais, fato que fica evidente em nossas cartas, quando o rei do Egito encomenda a Milkilu a compra de copeiras e envia o equivalente a 160 diban.

Mas se, anteriormente, nos séculos 19 e 20 a.C., a presença egípcia era caracterizada como uma forma de exploração imperial, com forte pressão militar, no período das cartas (século 14 a.c, durante os reinados de Ame- 
nhotep III 1389-1349 a.C., e/ou Amenhotep IV ou Akhenaton 1349-1333 a.C.) fica claro que Egito já não tem o controle das terras e são frequentes as revoltas e as coalizões anti-Egito. As cartas que estudamos mostram que o desinteresse egípcio pelas contendas entre vassalos provocou uma progressiva degradação do tecido político local, dando margem às usurpações, às conquistas e aos saques mútuos entre os pequenos reis (LIVERANI, p.461).

Finalmente, a troca estabelecida entre a cidade-estado de Gezer e Egito também representou elementos positivos para o desenvolvimento da cultura da região, tendo em conta que na cidade deve ter existido uma escola de escribas, focada na manutenção da administração e do comércio. Houve, assim, uma circulação constante de artesãos, escribas e diversos objetos, fato evidenciado pelos achados arqueológicos.

Vita (citado por GOREN, Y; FINKELSTEIN, I.; NA'AMAN, p. 279) examinou recentemente um grupo de cartas cananitas enviadas desde Gezer e outras cidades vizinhas. Concluiu que o mesmo escriba escreveu cerca de 24 cartas, que ele rotulou como 'Corpus de Gezer'. Entre elas estão as cartas de Shuwardata (EA 278-280), de Ba'lu-dāni [..] (EA 272), da Rainha dos leões (EA 273-274), de Ya 'zib-Hadda (EA 275-276), uma carta de Tagi (EA 266) e uma carta de Ya 'tiri (EA 296).

De acordo com a análise petrográfica, as cartas de outras cidades nessa lista (EA 278-280, 275-276, 266, 296), exceto EA 272 (e possivelmente EA 273-374), não foram enviadas desde Gezer. Assumindo que as conclusões de Vita (que se baseiam em observações já feitas por Knudtzon) são válidas, pode-se propor que o escriba de Gezer viajou para as cidades vizinhas, cujos governantes eram aliados de Gezer (por exemplo, Ginti-kirmil, Gath, possivelmente Ashdod) e escreveu as cartas em nome de seus governantes.

Além das referências aos três governantes da cidade de Gezer, também podemos concluir que:

1. Todas as cartas de Milkilu (EA 268-271) e Ba'lu-dānu (EA 292) foram escritas em Gezer, enquanto, das cinco cartas enviadas por Yapahu, apenas uma foi escrita ali (EA 297) e as outras (EA 298300, 378) foram enviadas desde Gaza.

Esta anotação ajuda a compreender a importância de Gezer na região. Parece que ali havia uma escola de escribas, o que também seria um testemunho da importância da cidade e do grau de desenvolvimento alcançado por ela. A cidade-estado constituía um ponto de referência fundamental para o controle da região dos baixios da Sefelá, estando localizada a meio caminho entre Gaza e Siquém. Além de ser uma cidade estratégica para o comércio, a constante 
correspondência e a possibilidade da existência de uma escola de escribas fazem da cidade um centro cultural muito importante para compreendermos o desenvolvimento da região.

2. Com relação aos três governantes, apesar de que as cartas não permitem concluir que se trate de pessoas de uma mesma família, a referência aos três governadores permite pensar na existência de uma sucessão no governo da cidade.

Pela correspondência analisada, percebemos que, dos três governantes mencionados, Milkilu parece ter sido o de maior influência: além de receber cartas do rei de Egito encomendando a compra de servos, servas, mulheres formosas para serem copeiras, ele também matinha comunicação frequente com o rei egípcio. Também vale a pena destacar suas alianças com governantes vizinhos (Shuwardata, Yanhamu), e seus vínculos com Tagi, seu sogro, governante de Ginti-Kirmil.

Só duas cartas mencionam Ba lu-dāni, destacando que se trata de um servo leal ao rei e que guarda o território a ele encomendado. Ele seria testemunha do avanço dos 'apîru na região, motivo pelo qual escreve solicitando ajuda do rei do Egito.

A duração do reinado de Yapahu parece ter sido breve e ele nunca conseguiu superar os problemas internos que enfrentava e estabilizar seu governo. Yapahu deve ter ido para Gaza em um esforço para obter o apoio das tropas egípcias, a fim de esmagar a rebelião em sua cidade-estado, e nesta ocasião escreveu e enviou suas cartas ao faraó.

3. Duas cartas fazem referência ao comércio de mulheres, de servos e servas. Em EA 268, o governador da cidade informa que está remitindo para o serviço do rei quarenta e seis servas, cinco servos e cinco ašîrûma. O envio dessas pessoas é feito por meio do emissário do rei, Haya. No entanto, não fica claro se estas pessoas são enviadas como um presente para o rei, ou se elas são pagamento de tributo ou, finalmente, se formam parte de uma transação comercial entre o governador de Gezer e o rei do Egito.

Um pouco diferente é a situação presente em EA 369, uma carta endereçada para Milkilu, onde o rei encomenda a compra de mulheres bonitas para servir como copeiras. O texto esclarece o tipo de peso (160 diban) utilizado na negociação, assim como o valor de cada uma das copeiras: quarenta (siclos de) prata é o preço de uma 
mulher copeira. Esses fatos permitem afirmar que havia um fluxo mais ou menos constante de produtos, pessoas e objetos entre o centro do império egípcio e as cidades-estado de Canãa e que o tipo de relacionamento estabelecido entre os governantes não era propriamente de vassalagem, nem de controle político-econômico e militar, mas de alianças estratégicas com fins comerciais, segundo a afirmação de LIVERANI (2016, p.467).

4. Segundo RAINEY (2015, p.31-35), sujeitos constantemente mencionados nas cartas são os 'apîru. Os 'apîru (termo semítico Ocidental) e seu sumério ideográfico reflexo, SA.GAZ (às vezes apenas GAZ nos textos de Amarna), estão documentados através de 800 anos de história, desde Ur, no terceiro milênio, até a XX dinastia egípcia. Eles nunca são mencionados como pastores, e os nomes preservados que possuem esta designação não constituem um grupo. Há 'apiru de origem semita, hurriata e outros. Na correspondência de Abdi-Heba de Jerusalém (EA 285-291) 'apîru serve como uma designação pejorativa, dos opositores, que são acusados de agir contra os interesses do rei do Egito.

É verdade que eles são frequentemente encontrados em busca de refúgio em áreas montanhosas, como refugiados políticos em Ammia que se uniram a Idrimi. Mas 'apîru se encontra um século mais tarde na mesma área geral onde 'Abdi-Ashirta os recrutou para se tornar sua milícia. A correspondência de Rib-Haddi deixa claro que muitos dos homens 'apîru eram militares qualificados (como Idrimi). Eles continuaram submetidos para sustentar seu filho. Labayu usou-os para realizar suas agressões contra cidades nos vales de Dothan e Jezreel. Como recompensa, ele estava dando aos 'apîru terras e propriedades (entre as terras agrícolas do vale de Jezreel, que eram, na verdade, uma posse faraônica).

Como homens com formação militar, são semelhantes aos mercenários. Foram contratados pelas autoridades competentes, faziam parte da "legião estrangeira" egípcia. Na tabuleta EA 195, Biryawaza, o autor dessa carta, tinha contratado mercenários, que certamente eram marginalizados da sociedade urbano-estatal, ao lado de uma unidade de guerreiros nômades, os Sutû. Aliás, isso mostra que os mercenários nômades nunca foram confundidos com homens urbanizados. Os registros indicam que o exército estava sendo empregado e, ao lado deles, o pessoal mercenário da "legião estrangeira" também 
estava cumprindo essas tarefas. Não há qualquer razão que seja para equiparar os 'apîru aos hebreus no Egito, nem social, nem histórica, nem linguisticamente.

\section{Referências bibliográficas}

GOREN, Y; FINKELSTEIN, I.; NA'AMAN, N. (eds.), Inscribed in clay: provenance study of the Amarna letters and other ancient Near Eastern texts. Tel Aviv: Tel Aviv University, 2004.

LIVERANI, Mario. Antigo Oriente: história, sociedade e economia. São Paulo: Editora da Universidade de São Paulo. 2016.

MYNAROVA, Jana. Language of Amarna - Language of diplomacy: perspectives on the Amarna letters. Prague: Czech Institute of Egyptology Faculty of Arts, Charles University in Prague, 2007.

MYNÁROVÁ, Jana. Expressions of dates and times in the Amarna letters. Ägypten un Levante, 21, p. 123-128, 2011.

MORAN, William L. (ed. e trad.). The Amarna Letters. Baltimore: The John Hopkins University Press, 1992.

RAINEY, Anson F. (org. e trad.). The El-Amarna correspondence: a new edition of the cuneiform letters from the site of El-Amarna based on collations of all extant tablets. Edição de William M. Schniedewind. Leiden: Brill, 2015, v. 1.

Submetido em: 18-5-2018

Aceito em: 24-5-2018 